\title{
Virtual environments increase participation of children with cerebral palsy in robot-aided treadmill training
}

\section{Conference Paper}

Author(s):

König, Alexander; Brütsch, Karin; Zimmerli, Lukas; Guidali, Marco; Duschau-Wicke, Alexander; Wellner, Mathias; Meyer-Heim, Andreas; Lünenburger, Lars; Köneke, Susan; Jancke, Lutz; Riener, Robert

Publication date:

2008

Permanent link:

https://doi.org/10.3929/ethz-a-006109319

Rights / license:

In Copyright - Non-Commercial Use Permitted

Originally published in:

https://doi.org/10.1109/ICVR.2008.4625147 


\title{
Virtual environments Increase Participation of Children with Cerebral Palsy in Robot-Aided Treadmill Training
}

\author{
Alexander Koenig ${ }^{1)}$, Student Member, IEEE, Karin Brütsch ${ }^{1)}$, Lukas Zimmerli, Marco Guidali, \\ Alexander Duschau-Wicke, Mathias Wellner, Andreas Meyer-Heim, Lars Lünenburger, Member, \\ IEEE, Susan Koeneke, Lutz Jäncke and Robert Riener, Member, IEEE
}

\begin{abstract}
Virtual environments can make repetitive motor rehabilitation exercises more motivating and thereby more effective. We hypothesize that participation-dependent multimodal stimuli increase the patient's activity as expressed through force exertion during robot-aided treadmill training. In a single case study with one patient (12 years old), we were able to show that active participation increased in the presence of visual stimuli and decreased in their absence. For a feasibility study, we included four children with cerebral palsy in order to assess the user acceptance of four different virtual environment scenarios including a soccer scenario, a traffic situation, obstacle crossing and wading through deep snow. Using questionnaires, we found that only the soccer scenario provided sufficient interactive elements to engage the patients.
\end{abstract}

\section{INTRODUCTION}

$\mathrm{C}$ EREBRAL Palsy (CP) affects approximately 1.5 out of 1,000 children [9] and results in a wide variety of cognitive and motor impairments. Treadmill training is part of a rehabilitation program administered to $\mathrm{CP}$ patients in order to improve existing but limited walking capabilities [2]. The Lokomat gait orthosis was developed in the Spinal Cord Injury Center at the University Hospital Balgrist,

Manuscript received April 15, 2008.

The research leading to these results has received funding from the European Community's Seventh Framework Program (FP7/2007-2013) under grant agreement $\mathrm{n}^{\circ} 215756$.

A. Koenig is supported by the National Center of Competence in Research (NCCR). K. Brütsch is supported by the Olga Mayenfisch Stiftung, Zurich and Schweizerische Stiftung für das cerebral gelähmte Kind, Switzerland.

A. Koenig is with the Sensory-Motor Systems Laboratory, ETH Zurich, CH-8092 Zurich, Switzerland and also with the Spinal Cord Injury Center, Balgrist University Hospital, CH-8008 Zurich, Switzerland (phone:+41 44 3863739 ; e-mail: Koenig@mavt.ethz.ch).

K. Brütsch, S. Koeneke, and L. Jäncke are with the Institute of Psychology, Division Neuropsychology of the University of Zurich, CH8050 Zurich, Switzerland (e-mail: k.bruetsch@psychologie.uzh.ch).

L. Zimmerli is with Hocoma AG, CH-8604 Volketswil, Switzerland and also with the Sensory-Motor Systems Laboratory, ETH Zurich, CH-8092 Zurich, Switzerland.

M. Guidali, M. Wellner and R. Riener are with the Sensory-Motor Systems Laboratory, ETH Zurich, CH-8092 Zurich, Switzerland and also with the Spinal Cord Injury Center, Balgrist University Hospital, CH-8008 Zurich, Switzerland.

A. Duschau-Wicke is with the Sensory-Motor Systems Laboratory, ETH Zurich, CH-8092 Zurich, Switzerland and also with the Hocoma AG, CH8604 Volketswil, Switzerland.

M. Meyer-Heim is with the Rehabilitation Center Affoltern a.A. of the University Childrens Hospital Zurich, CH-8032 Zurich, Switzerland.

L. Lünenburger is with Hocoma AG, CH-8604 Volketswil, Switzerland. 1) The authors Koenig and Brütsch contributed equally to this work and agreed to share first authorship
Zurich, Switzerland, for the improvement and automation of neuro-rehabilitative treadmill training [3]. It consists of two actuated leg orthoses, which are strapped to the patient's legs. On each orthosis, two motors (one at the hip joint and one at the knee joint) guide the patient's legs on a physiological walking pattern. A pediatric version of the Lokomat has been recently developed and provides automated treadmill training for children aged four and up



Fig. 1. The Pediatric Lokomat (Image courtesy of Hocoma AG, Volketswil, Switzerland).

[14].

Virtual environments (VE) in rehabilitation provide motivating training that can be superior to training in a real situation [6], [15]. It was shown that increased motivation [10], [11] and active participation [7] can lead to increased efficiency and advancements of motor learning in neurorehabilitation. Children in particular have little motivation towards the training process, as the training is too 
monotonous and lacks a stimulating entertainment. Enriched environments, highly functional and task-oriented practice environments were shown to be necessary for motor relearning and recovery after stroke [7].

We hypothesize that patient participation as expressed through force exertion on the Lokomat during walking can be influenced by visual stimuli of a virtual environment. Our goal is individuated control over the visual stimuli: increasing participation as needed to maximize the success of rehabilitation, while appropriately decreasing participation before the patient becomes overstrained.

\section{METHODS}

\section{A. Virtual Environment System Setup}

Therapeutic training goals for specific motor deficits of subjects with CP were identified to be (i) the increase of maximal force output of hip and knee flexors/extensors, (ii) speed adaptation during walking, (iii) translation of visual input into motor output (eye/limb coordination) and (iv) in a previous paper [8].

The VE setup around the Lokomat ${ }^{\circledR}$ Pro system (Hocoma AG, Volketswil, Switzerland) includes a 42 inch flat screen and a 7.1 Dolby surround sound system. The graphic elements are programmed using the Ogre framework (www.ogre3d.org), and the graphics models are created in Maya (www.adobe.com). The Fmod programmers API provides the framework for sound output (www.fmod.org).

The Lokomat is used as an input device of the patient's movements into the VE. An avatar in the VE mimics the movements of the patient. Additionally, it serves as a haptic display. Thereby force feedback of interactions of the virtual avatar with virtual objects is applied to the legs of the patient. The snow, the obstacle and the soccer scenarios include haptic interaction. Snow friction is implemented as a viscous friction force with quadratic velocity dependency. Coupling the lower leg's velocity with the friction force in the thigh produces the impression of snow friction. The haptic feedback of the obstacles is implemented as a spring damper system and includes a force feedback in normal and
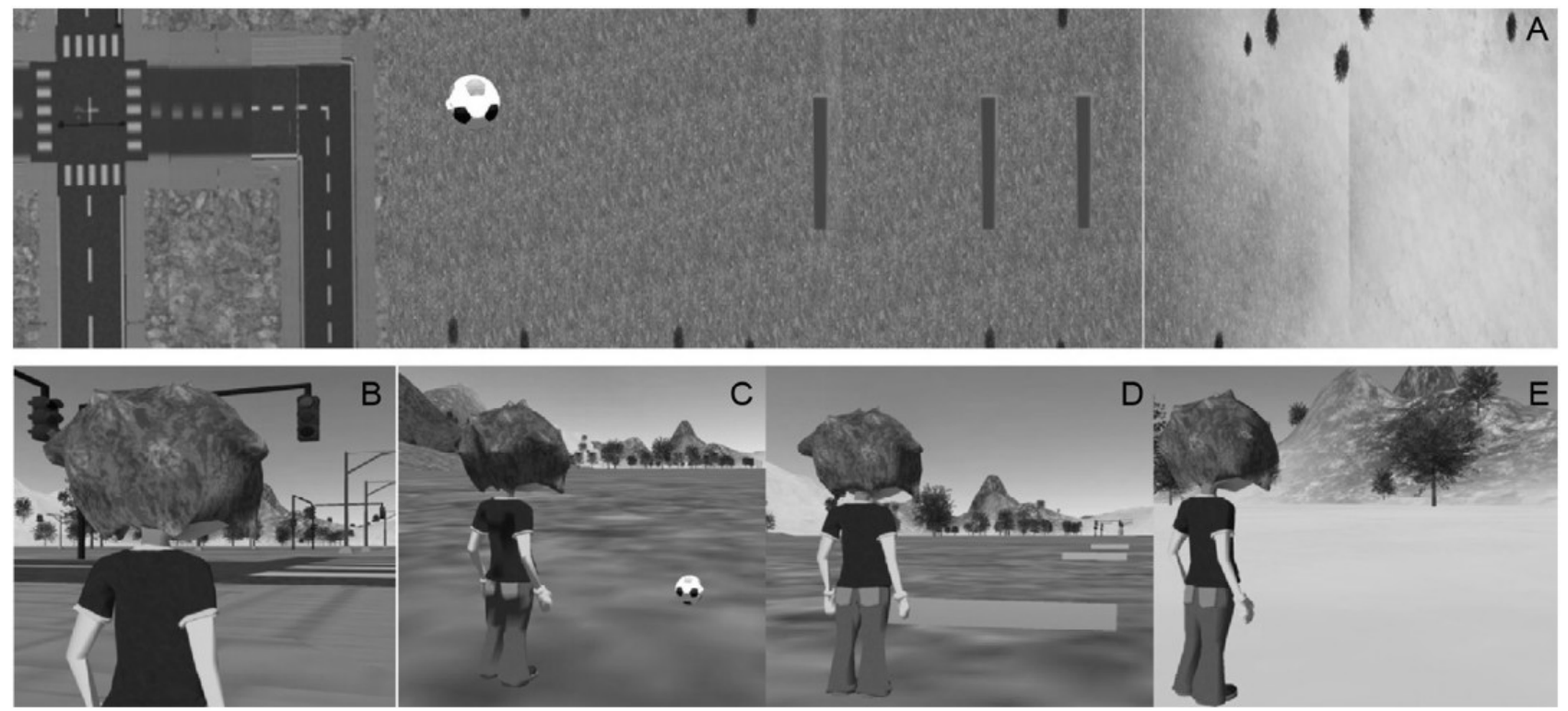

Fig . 2. Overview of the virtual gait parcours (courtesy: Hocoma AG.). (A) Parcour of bird's eye view of all four scenarios. (B) Avatar at traffic light. (C) Soccer scenario. (D) Obstacles scenario and (E) Avatar walking through snow.

initiation and termination of gait.

We implemented a total of four training scenarios (Error!

Reference source not found.) that address the afore mentioned training goals, including three with virtual ADL tasks and one non-ADL task. For strengthening muscles and increasing the range of motion, the patients wade through deep snow in a virtual environment or kick a virtual soccer ball. In order to exercise the starting and stopping of walking movements and the change of walking speed, the patients have to walk within a street traffic scenario, i.e. crossing a street at a traffic light. Patients exercise gait-eye coordination (translation of visual input into motor output) and leg motion coordination in the street traffic scenario and in an obstacle course. We described details of the scenarios tangential direction. The soccer simulation produces a physically realistic output force on ball contact [8].

We provided three different modes of task difficulty from A to $\mathrm{C}$ depending on the severity of the disability. This makes the VE training challenging, yet feasible, for all patient groups. For clinical use in mode A, the Lokomat is position-controlled, actively moving the patient on the walking trajectory. To give the patient more control over the task, mode B provides $100 \%$ guidance force with the possibility of free movements during discrete events, e.g. for the swing leg during the kick of a soccer ball. Mode $\mathrm{C}$ employs a so-called path controller, giving the patient freedom in timing, whereas the robot merely ensures the spatial movement path and provides assistive force as 
necessary [5]. Each task has several levels of difficulty and employs some or all of the three modes. For the studies described in this paper, we only used modes A and B.

\section{B. Biofeedback as Outcome Measures of Active Participation}

Patient activity and participation during Lokomat training is quantified by weighted force measurements, the so-called biofeedback values [12]. The forces were measured in series with the spindle gear drives of the Lokomat (Error! Reference source not found.). The therapist cannot assess the activity level of the patient manually, because there is no physical interaction between the patient and the therapist in robotic automation gait training.

The biofeedback values are weighted averages of the forces at the hip and knee joints, calculated for stance and swing phase. The weighting functions were defined for each part of the gait cycle, such that the resulting biofeedback values increase for therapeutically desirable movements, e.g. knee flexion for early swing.

Force measurement $F_{i}$ at time $t_{k}$ is weighted with $w_{i, j}$ and scaled with the offset $\mathrm{o}_{\mathrm{i}, \mathrm{j}}$. Thereby $i \in[0,1]$ with 0 being the hip joint and 1 the knee joint and $j \in[0,1]$ where $\mathrm{j}=0$ is the stance and $j=1$ the swing phase. Details of the computation

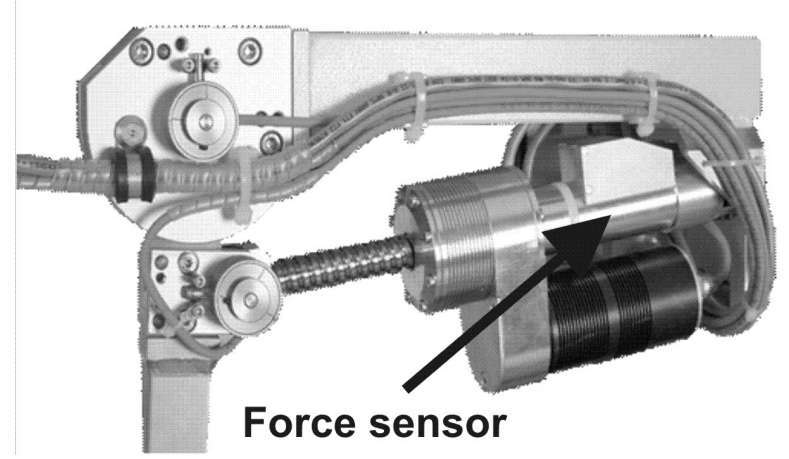

Fig. 4. Force sensor on the right hip joint of the Lokomat (Image courtesy of Hocoma AG, Volketswil, Switzerland).

and the weight functions can be found in [13]. The biofeedback values are unit less, positive when the patient is actively participating and negative when the Lokomat carries the burden of moving the patient.

Comparing the biofeedback values of one subject over several Lokomat training sessions is tempting but not directly possible. Slightly altered attachment of the orthosis on the legs of the patients during the training session can lead to changes in the absolute values. The comparison between biofeedback values for training with and without $\mathrm{VE}$ as a measure of active participation is also difficult, as the patients without VE are typically motivated by the therapist. This is not the case for training with VE.

We implemented a virtual opponent in the soccer scenario that plays soccer against the patient (Fig. 3). The patient steers his avatar through the virtual environment. The opponent is configured to walk faster than the patient when the patient's biofeedback is low and slower when the patient participates actively. As an additional motivation factor, the opponent is able to take over the soccer ball from the avatar when he is ahead of the avatar. When walking behind the opponent, the avatar is able to catch up by actively participating and producing high biofeedback values. Whereas the position of the subject's avatar is computed as an integral over the walking speed, the position of the opponent in the virtual environment is calculated with an additional, biofeedback dependent speed adaptation factor $\Delta \mathrm{v}$.

$$
x_{\text {Opponent }}=\int\left(v_{\text {tm }}+\Delta v_{\text {Opponent }}+v_{\text {Offset }}\right) d t .
$$

Where $\mathrm{v}_{\mathrm{tm}}$ is the treadmill speed and

$$
\Lambda v_{\text {Opponent }}=G \cdot \operatorname{sig}\left(\sum_{i=1}^{N} \frac{1}{N} B f_{i}\right), i \in[1,2,3,4]
$$

is a velocity offset set by the therapist. $\mathrm{BF}_{1}=$ biofeedback hip left, $\mathrm{BF}_{2}=$ biofeedback knee left, $\mathrm{BF}_{3}=$ biofeedback hip right, $\mathrm{BF}_{4}=$ biofeedback knee right. The multiplier $\mathrm{G}$ scales the minimal and maximal deviation of the biofeedback dependent walking speed component. $\mathrm{G}=1$ scales the maximal deviation $\Delta \mathrm{v}_{\text {Opponent }}$ to $\pm 1 \mathrm{~m} / \mathrm{s}$.

Within the VR, the camera is positioned 1.68 meters shifted slightly to the right behind the avatar (Fig. 3B). When the

A

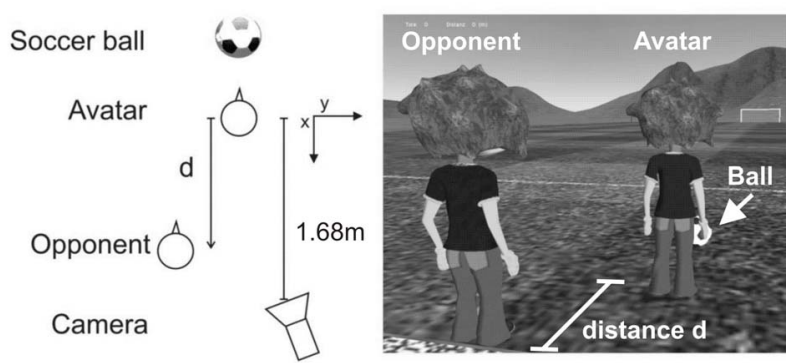

Fig. 3. A: Schematic drawing of the relationship between the avatar and the opponent. The distance $\mathrm{d}$ becomes larger for increasing lead of the avatar over the opponent. When the opponent is closer than $1.68 \mathrm{~m}$ he reaches the field of view of the avatar. A negative distance $\mathrm{d}$ is equivalent to a lead of the opponent over the avatar. B: Screenshot from the VE

opponent is more than $1.68 \mathrm{~m}$ behind the avatar he is not visible on the screen.

We expect the visibility of the opponent to increase and the absence of the opponent to decrease active participation during Lokomat training. Compared to the pure display of numerical biofeedback feedback values, the opponent provides the possibility to produce a challenging situation on demand of the therapist. 
TABLE I

DESCRIPTION OF THE PATIENTS IN THE FEASIBILITY STUDY

\begin{tabular}{|c|c|c|c|c|c|c|c|c|}
\hline $\begin{array}{c}\text { Patient } \\
\text { No. }\end{array}$ & Sex & $\begin{array}{c}\text { Age } \\
(y ; m)\end{array}$ & $\begin{array}{c}\text { Height } \\
\text { (cm) }\end{array}$ & Diagnosis & $\begin{array}{c}\text { Number of training } \\
\text { sessions } \\
\text { with VE }\end{array}$ & $\begin{array}{c}\text { Mean } \\
\text { training } \\
\text { duration } \\
\text { (min) }\end{array}$ & $\begin{array}{c}\text { Mean } \\
\text { walking } \\
\text { distance } \\
\text { (m) }\end{array}$ & $\begin{array}{c}\text { Mean } \\
\text { walking } \\
\text { velocity } \\
\text { (km/h) }\end{array}$ \\
\hline 1 & $\mathrm{~F}$ & $10 ; 4$ & 138 & BS-CP $(I I I)^{a}$ & 13 & 26.22 & 693.85 & 1.64 \\
\hline 2 & $\mathrm{~F}$ & $12 ; 11$ & 154 & BS-CP (II) & 15 & 28.21 & 845 & 1.77 \\
\hline 3 & $M$ & $13 ; 3$ & 155 & $\mathrm{TBI}^{\mathrm{b}}$ & 5 & $25: 07$ & 722.60 & 1.74 \\
\hline 4 & $\mathrm{M}$ & $12 ; 4$ & 150 & $\mathrm{MMC}^{\mathrm{C}}$ & 4 & $23: 38$ & 664 & 1.67 \\
\hline
\end{tabular}

We filtered the position data of the opponent with a low pass filter of $2 \mathrm{~Hz}$ in order to eliminate noise that was inserted as an artifact of the recording procedure. $2 \mathrm{~Hz}$ appeared reasonable as the patient would not perceive and react to position changes of the avatar above this cut off frequency.

\section{Clinical methods}

We first performed a feasibility study to assess user acceptance for all four scenarios and to identify the most engaging scenario. The most engaging scenario was then used in a second study. In this second study, we investigated the influence of the VE onto the participation of patients.

Both studies were conducted at the rehabilitation center Affoltern am Albis of the University Children's Hospital Zurich, Switzerland. Approval for the studies was obtained from local ethics committees, and the legal guardians of all patients gave written informed consent. Patients were eligible for the study if they had central gait impairment due to either congenital or acquired brain or spinal lesions. Femur length had to be at least $21 \mathrm{~cm}$, which includes children from above four years. Further, patients had to be able to signal pain, fear or discomfort and had to be cooperative.

A total of four patients (Error! Reference source not found.) were included in the feasibility study to assess the developed VE-based technologies (mean age 12.4 years, std. 1.5 years). The aims of study were (a) to determine whether patients quickly learned to use the system in order to perform the four different scenarios, and (b) to assess the patient motivation for the four different scenarios.

We observed how the patients interacted in the virtual environment and evaluated the psychological effects of the scenarios (attention, concentration and motivation) by using motivational questionnaires (Pediatric Volitional Questionnaire PVQ) [1] for therapists and a self generated motivation questionnaire for children. We asked the participants to rate their experience in the VE concerning their interest in the scenario, their own perceived competence, the value of the VE training and their own effort during the training (Error! Reference source not found.).

The second study was performed with a twelve year old patient, diagnosed with bilateral spastic cerebral palsy, who had a Gross Motor Function Classification level of three (GMFCS). The aim was to evaluate the influence of the VE on the participation of the patient. Based on questionnaire results of the feasibility study, we decided to perform further studies only on the soccer scenario, which the subjects of the feasibility study evaluated to be most motivating. The obstacle, snow and traffic scenarios in the current state of development were not sufficiently engaging, as they were not sufficiently interactive. The subject walked for several training sessions without VE and one session in the soccer scenario. The opponent was visible for the patient only after he approached the patient avatar with to a distance of approximately $1.68 \mathrm{~m}$ (Fig. 3). Within the soccer scenario, difficulty settings were: guidance force $100 \%$, reduction in guidance force during soccer ball kicking: 95\%, walking speed varied between $1.5 \mathrm{~km} / \mathrm{h}$ and $2.3 \mathrm{~km} / \mathrm{h}$.

\section{RESULTS AND DISCUSSION}

For the feasibility study, the questionnaire revealed that three of the four scenarios (traffic, snow, obstacle) lacked motivational and attention aspects. Three of the four patients judged the soccer scenario to be most engaging. One patient judged the obstacles and traffic scenario as most engaging. All verbalized the benefit of the Lokomat training as necessary to improve their walk. One patient accredited his newly acquired ability to walk without crutches to the VE based Lokomat training. Furthermore, all patients expressed their wish to use the VR system on an ongoing basis. All four expressed a desire for more interaction to influence the virtual environment.

We performed a second study on the influence on the participation of the most engaging VE scenario, which was identified to be the soccer scenario. This second study consisted of a 29-minute training session in the virtual soccer scenario walking against an opponent that could overtake the avatar and take away the soccer ball. Results of the second study show an increase of biofeedback values corresponds to an increase in active patient participation. This key definition was justified in the methods section. We compared biofeedback values depending on the distance of the opponent from the avatar. The minimal and maximal biofeedback values during the whole training duration were 22.9 and 235.0.

We found increased mean biofeedback values for the time the opponent was visible and decreased values when the opponent was not visible. Quantitative results are displayed in Table II. For 77.2 percent of the training duration, a visible/non visible opponent coincided with above mean/below mean biofeedback values. 
TABLE II

\begin{tabular}{|c|c|c|c|c|c|c|}
\hline & \multirow{2}{*}{ Specific Question } & \multicolumn{4}{|c|}{$\begin{array}{r}\text { Score } \\
(5=\text { Yes, very much, } 1\end{array}$} & \multirow[t]{2}{*}{ Average } \\
\hline & & Patient 1 & Patient 2 & Patient 3 & Patient 4 & \\
\hline (1) Interest: & $\begin{array}{l}\text { - Did you have fun to do the training? } \\
\text { - Which scenario did you like most? } \\
\text { - Do you look forward to the next training? }\end{array}$ & $\begin{array}{l}5 \\
\text { Obstacles } \\
5\end{array}$ & $\begin{array}{c}4 \\
\text { Soccer } \\
4\end{array}$ & $\begin{array}{c}4 \\
\text { Soccer } \\
3\end{array}$ & $\begin{array}{l}3 \\
\text { Soccer } \\
3\end{array}$ & $\begin{array}{l}4 \\
\text { Soccer } \\
3.75\end{array}$ \\
\hline $\begin{array}{l}\text { (2) Perceived } \\
\text { Competence }\end{array}$ & $\begin{array}{l}\text { - Do you think you did well at this training? } \\
\text { - Dou you think you improved your training? }\end{array}$ & $\begin{array}{l}5 \\
5\end{array}$ & $\begin{array}{l}4 \\
5\end{array}$ & $\begin{array}{l}2 \\
4\end{array}$ & $\begin{array}{l}3 \\
4\end{array}$ & $\begin{array}{l}3.5 \\
4.5\end{array}$ \\
\hline $\begin{array}{l}\text { (3) Value / } \\
\text { Usefulness }\end{array}$ & $\begin{array}{l}\text { - Do you believe this training could be } \\
\text { beneficial to you? } \\
\text { - For what could this training be useful? }\end{array}$ & $\begin{array}{l}\quad 5 \\
\text { to walk } \\
\text { without } \\
\text { crutches }\end{array}$ & $\begin{array}{l}5 \\
\text { to walk } \\
\text { better }\end{array}$ & $\begin{array}{l}5 \\
\text { to walk } \\
\text { better }\end{array}$ & $\begin{array}{l}4 \\
-\end{array}$ & 4.75 \\
\hline (4) Effort & $\begin{array}{l}\text { - How much effort did you put in the training } \\
\text { today? } \\
\text { - How important is it to you to do well at this } \\
\text { activity? }\end{array}$ & 5 & 5 & $\begin{array}{l}2 \\
4\end{array}$ & $\begin{array}{l}3 \\
3\end{array}$ & $\begin{array}{r}3.75 \\
4\end{array}$ \\
\hline
\end{tabular}

Exemplary,

Fig. 5 shows a quantitative plot of the absence respectively presence of the opponent overlaid with the biofeedback plot

For the time span $[16 ; 77]$ or $[305 ; 444]$ second, the distance $\mathrm{d}$ between opponent and avatar was larger than $1.68 \mathrm{~m}$, the opponent was not visible and the biofeedback at that time was below the mean biofeedback. Conversely, for time $[632 ; 665]$ or $[763 ; 799]$ seconds, the opponent position was visible with a maximal distance of $1.68 \mathrm{~m}$ behind the avatar or even in front of the avatar. The biofeedback for these intervals increased over the mean biofeedback. During the training, the patient was able to keep the avatar for 25 minutes 13 seconds ahead of the opponent ( 87 percent of the

\section{CONCLUSION AND OUTLOOK}

We were able to show that the presence of a virtual opponent in a VE produced higher participation of children with congenital or acquired gait impairment when compared to the absence of this visual stimulus. Future development of the scenarios must focus on the implementation of interactive, motivating elements. Further improvements in the soccer scenario are necessary to maintain high motivation during longer Lokomat trainings. The results of the single case study are part of the design process of the clinical study with control and intervention groups that will



Fig. 5. Sum of the swing phase biofeedback values of both hip and knee joints for one training session. The mean biofeedback value is 55.8 . The gray lines indicates when the opponent was visible or not from the patient's perspective

total training duration) and kicked the soccer ball 35 times. be performed in the future.

The opponent took over the ball 5 times and kicked it 
TABLE III

\begin{tabular}{|c|c|c|}
\hline \multicolumn{3}{|c|}{$\begin{array}{c}\text { MEAN BIOFEEDBACK VALUES AND STANDARD DEVIATION } \\
\text { FOR THE OVERALL BIOFEEDBACK, THE CASE WHEN THE } \\
\text { OPPONENT WAS VISIBLE AND THE CASE WHEN THE } \\
\text { OPPONENT WAS NOT VISIBLE. }\end{array}$} \\
\hline & \multicolumn{2}{|c|}{ Biofeedback } \\
\hline & Mean & Std. \\
\hline Total & 55.8 & 52.4 \\
\hline Opponent visible $(\mathrm{d}<1.68 \mathrm{~m})$ & 105.6 & 50.3 \\
\hline Opponent not visible $(\mathrm{d}>=1.68 \mathrm{~m})$ & 33.7 & 35.4 \\
\hline
\end{tabular}

\section{ACKNOWLEDGMENT}

We want to thank the movement scientists and physiotherapy team for their cooperation and help during the measurements. We also thank the children, who participated in this study.

\section{REFERENCES}

[1] S. Basu, A. Kafkes, R. Geist and G. Kielhofner, "Pediatric Volitional Questionnaire. Model of human," Occupation 2002.

[2] R. J. Cherng, C. F. Liu, T. W. Lau and R. B. Hong, "Effect of treadmill training with body weight support on gait and gross motor function in children with spastic cerebral palsy," Am J Phys Med Rehabil 86: 548-555, 2007.

[3] G. Colombo, M. Joerg, R. Schreier and V. Dietz, "Treadmill training of paraplegic patients using a robotic orthosis," J Rehabil Res Dev 37: 693-700, 2000.

[4] A. W. Dromerick, D. F. Edwards and M. Hahn, "Does the application of constraint-induced movement therapy during acute rehabilitation reduce arm impairment after ischemic stroke?" Stroke 31: 2984-2988, 2000

[5] A. Duschau-Wicke, J. Zitzewitz, M. Wellner M, A. Koenig, L. Lünenburger and R. Riener, "Path Control: A Strategy for PatientCooperative Training of Gait Timing," Fortschritt-Berichte VDI 17: 2, 2007

[6] M. K. Holden, "Virtual environments for motor rehabilitation: review," Cyberpsychol Behav 8: 187-211; discussion 212-189, 2005.

[7] M. J. Johnson, "Recent trends in robot-assisted therapy environments to improve real-life functional performance after stroke," J Neuroeng Rehabil 3: 29, 2006.

[8] A. Koenig, M. Wellner, S. Koneke, A. Meyer-Heim, L. Lunenburger and R. Riener, "Virtual gait training for children with cerebral palsy using the Lokomat gait orthosis," Stud Health Technol Inform 132: 204-209, 2008

[9] L. A. Koman, B. P. Smith and J. S. Shilt, "Cerebral palsy," Lancet 363: 1619-1631, 2004.

[10] D. G. Liebermann, A. S. Buchman and I. M. Franks, „Enhancement of motor rehabilitation through the use of information technologies," Clin Biomech (Bristol, Avon) 21: 8-20, 2006.

[11] R. Loureiro, F. Amirabdollahian, S. Cootes, E. Stokes and W. Harwin, "Using haptics technology to deliver motivational therapies in stroke patients: Concepts and initial pilot studies," Proceedings of EuroHaptics 2001 6, 2001.

[12] L. Lunenburger, G. Colombo and R. Riener, "Biofeedback for robotic gait rehabilitation," J Neuroengineering Rehabil 4: 1, 2007.

[13] L. Lunenburger, G. Colombo, R. Riener and V. Dietz, "Biofeedback in gait training with the robotic orthosis Lokomat,", Conf Proc IEEE Eng Med Biol Soc 7: 4888-4891, 2004.

[14] A. Meyer-Heim, I. Borggraefe, C. Ammann-Reiffer, S. Berweck, F. H. Sennhauser, G. Colombo, B. Knecht and F. Heinen, "Feasibility of robotic-assisted locomotor training in children with central gait impairment," Dev Med Child Neurol 49: 900-906, 2007.

[15] H. Sveistrup, "Motor rehabilitation using virtual reality," J Neuroeng Rehabil 1: 10, 2004. 